\title{
Se vencer o Palestra, vence a "bella" e legendária pátria italiana: um estudo comparado dos Palestras Itália de São Paulo e de Belo Horizonte (1914-1933)
}

\author{
If win the Palestra, wins the "beautifull" and legendary Italian homeland: a \\ comparative study of Palestras Itália São Paulo and Belo Horizonte (1914-1933)
}

\author{
Rodrigo Caldeira Bagni Moura \\ Universidade Salgado de Oliveira, Belo Horizonte / Brasil \\ Doutor em História Comparada, UFRJ \\ rodrigo.caldeira@ig.com.br
}

\begin{abstract}
ReSUMO: No presente trabalho analisaremos em perspectiva comparada o Palestra Itália fundado em São Paulo em 1914, que após 1942 passou a se chamar Sociedade Esportiva Palmeiras, com o Palestra Itália de Belo Horizonte, que iniciou suas atividades em 1921 e após 1942 se transformou em Cruzeiro Esporte Clube. Nosso objetivo central será analisar comparativamente o processo de afirmação dos dois times, buscando compreender qual a importância do futebol, no processo de inserção e pertencimento dos italianos nas duas capitais mencionadas, e qual a contribuição dos Palestras para sedimentar a noção de identidade italiana, entre os membros da colônia, no período de 1914 a 1933. Durante a pesquisa pudemos perceber que vencer, para os Palestras Itália de São Paulo e de Minas Gerais, passou a ser uma forma de conseguir reunir e agrupar mais pessoas, que vieram da região onde se constituiu o território italiano após a unificação, em torno de um sentimento de pertencimento, reforçando desse modo a italianidade.
\end{abstract}

Palavras-Chave: Palestra Itália; Futebol; Imigração; Italianos; Técnica.

ABSTRACT: In this paper we are going to analyze in comparative perspective, the Palestra Italia, founded in São Paulo in 1914, which after 1942 became known Sociedade Esportiva Palmeiras, with the Palestra Italia in Belo Horizonte, which began its activities in 1921 and after 1942 became Cruzeiro Esporte Clube. Our main objective is to comparatively analyze the process of affirmation of the two teams, trying to understand how important football is in the process of inclusion and belonging of the Italians in the two aforementioned capitals, and the contribution of both Palestra teams to settle the notion of Italian identity, and members of the colony, in the period 1914 to 1933. During the research we realized that winning, to SP and MG's Palestra Italia team, turned into a way of getting together and grouping more people, who came from the region where they formed an Italian territory after unification, around a sense of belonging, thereby strengthening the Italian identity.

KEYwoRDS: Palestra Itália; Football; Immigration; Italians; Technical. 


\section{O Futebol E A Fundação do Palestra Itália em São PaUlo e em Belo Horizonte}

0 encontro entre os dois Palestras foi ansiosamente aguardado pelos torcedores mineiros que sonhavam em ver o "clube de Ministrinho... o clube de Heitor... o clube de Serafini... o clube de Amilcar... Enfim, o Palestra de São Paulo, o clube de todos eles". ${ }^{1}$ Desde que os Palestras foram fundados seria a primeira vez que os mesmos se enfrentariam. A multidão "boquiaberta" parecia estar em êxtase nos momentos que antecediam a partida principal. 0 jogo do Guarany contra o Calafate, a preliminar do encontro, "serviria talvez para ilustrar a história do futebol, no capítulo da sua origem", 2 pois o jogo estava muito acirrado, com chutes que "transbordavam" o campo e pela "violência desgovernada das rebatidas".

Os mineiros aplaudiram os paulistas com muito entusiasmo nos instantes que antecederam a partida. As duas equipes estavam assim escaladas, pelo lado do Palestra de São Paulo: Russo; Nigro e Loschiavo; Ciglio, Gogliardo e Serafini; Ministrinho, Carrone, Heitor, Lara e Osses; pelo time do Palestra Mineiro, jogaram: Catalano; Rizzo e Nereu; Bento, Pires e Nino II, Piorra, Ninão, Carazzo, Bengala e Armandinho. Esse match foi a confirmação de um sonho de uma parcela dos italianos residentes em São Paulo e em Belo Horizonte, que lutou e se organizou para fundar dois times de futebol que reunissem e agrupassem os italianos, e também para disputarem, em condições dignas com os demais times da cidade, os principais campeonatos.

Antes da partida e para dar um "aspecto cívico à festa esportiva"3 houve hasteamento da bandeira e muitas cerimônias que o cronista classificou como "antiesportivas",4 discursos no meio do campo, para a embaixada e para os jogadores, que retardaram o início do jogo. Durante a partida,

o Palestra de São Paulo deslumbrou os mineiros, explorando inteligentemente as circunstâncias. Assim, o maior colaborador da vitória dos paulistas foi exatamente Ministrinho, que Heitor afastou de quase todos os ataques, por ser o jogador mais visado pela defesa dos mineiros. Nisto e em tudo o mais, Heitor se revelou um mestre. Marcado por Nininho, o melhor half do nosso Estado, Ministrinho teria poucas ocasiões. Heitor desviou sempre o jogo pela ala

\footnotetext{
${ }^{1}$ MINAS GERAES. Belo Horizonte, p. 2, 19-20 maio1930.

2 MINAS GERAES. Belo Horizonte, p. 2, 19-20 maio1930.

3 MINAS GERAES. Belo Horizonte, p. 2, 19-20 maio1930.

${ }^{4}$ MINAS GERAES. Belo Horizonte, p. 2, 19-20 maio1930.
} 
esquerda, reservando o extraordinário extrema direita para instantes especiais. Exatamente por isso, as poucas intervenções de Ministrinho foram fatais e ocasionaram os quatro gols dos paulistas. ${ }^{5}$

No fim do jogo, o placar não deixou dúvidas: o "Palestra de São Paulo venceu o Palestra de Belo Horizonte por quatro a dois". ${ }^{6}$ Essa partida foi muito comemorada em Belo Horizonte pelos dois times, e realmente os dois clubes tinham muito a festejar, pois, em pouco tempo de fundação das duas agremiações, conseguiram êxito na seara esportiva como poucas equipes haviam conseguido até aquele momento. $^{7}$

Neste trabalho compara-se o Palestra Itália fundado em São Paulo em 1914, que após 1942 passou a se chamar "Sociedade Esportiva Palmeiras", com o Palestra Itália de Belo Horizonte, que iniciou suas atividades em 1921 e após 1942 transformou-se em Cruzeiro Esporte Clube. 0 objetivo central é analisar, em perspectiva comparada, o Palestra Itália fundado em São Paulo com o Palestra Itália fundado em Belo Horizonte, buscando compreender qual a importância do futebol no processo de inserção e pertencimento dos italianos nas duas capitais mencionadas e qual a contribuição dos Palestras para sedimentar a noção de identidade italiana, entre alguns membros da colônia, no período de 1914 à 1933.

Especificamente, buscou-se compreender as semelhanças e dessemelhanças, no tocante à construção da ideia de pertencimento à Itália como nação de origem e ao Palestra como representante de uma parcela dos imigrantes que se agruparam em torno desse time de futebol, nas capitais dos Estados de São Paulo e de Minas Gerais, e na sua articulação com os demais clubes e com essa modalidade.

Em Minas Gerais, a impressão que as pessoas tinham do futebol paulista é de que ele era o melhor do Brasil. 0 jogo dos paulistas era superior até mesmo ao dos cariocas; era o melhor tecnicamente. E os cronistas ainda afirmavam: "São Paulo será ainda, por muito tempo, a terra do football". ${ }^{8} \mathrm{~A}$ disputa para confirmar qual

\footnotetext{
${ }^{5}$ MINAS GERAES. Belo Horizonte, p. 2, 19-20 maio1930.

${ }^{6}$ MINAS GERAES. Belo Horizonte, p. 2, 19-20 maio1930.

7 É impressionante observar como em pouco tempo de fundação os Palestras Itália conquistaram tantos títulos. O Palestra Itália de São Paulo foi campeão paulista em 1920, 1926, 1927, 1932, 1933 e 1934. O Palestra Itália de Belo Horizonte foi campeão mineiro em 1926, 1928, 1929 e 1930. As duas equipes foram vice-campeãs por diversas vezes no período que abrange esta pesquisa.

${ }^{8}$ MINAS GERAES. Belo Horizonte, p. 2, 19-20 maio 1930.
} 
região possuía o melhor futebol, nesse momento, concentrava-se entre esses dois Estados. O fato de o jogo dos mineiros ter melhorado muito e se desenvolvido tecnicamente durante a década de 1920, no entanto, foi uma observação, recorrente na imprensa, a tal ponto de os espectadores reconhecerem o lugar que Minas Gerais passara a ocupar na vida esportiva do país, a partir da década de 1930: "Nenhum clube desembarca aqui para debochar dos mineiros". ${ }^{9}$

É importante salientar que, ao ser difundido o "mito da italianidade" - e os Palestras contribuíram para reforçá-lo à medida que seus dirigentes e, posteriormente, os seus torcedores cultuavam os símbolos da pátria distante -, as hostilidades contra os italianos cresceram. Com a fundação e a ascensão do time de futebol que representava essa colônia, foram levadas para a esfera esportiva algumas discussões e sentimentos que se concentravam no âmbito da aceitação e da recusa da convivência social dos vários povos que viviam no Brasil nesse momento, que, de certa forma, disputavam espaço no mercado de trabalho e, de modo mais geral, no cotidiano das cidades.

Em razão da grande importância que o futebol assumiu, contudo, essa prática condensou e canalizou percepções, afirmações e representações dos italianos de forma crescente. Esse jogo, com o passar dos anos e numa velocidade impressionante, até para os maiores entusiastas, possibilitou o surgimento de grandes palcos onde as mais diferentes sensações foram experimentadas, sedimentando condutas, difundindo valores e abrangendo aspectos positivos e negativos da nossa cultura. Acrescenta-se a tudo isso o fato de o espetáculo esportivo ter-se transformado em algo rentável, capaz de despertar os mais diversos interesses.

Tanto o Palestra de São Paulo quanto o de Minas Gerais, apesar de enfrentarem em vários episódios muitas hostilidades e violências, conseguiram se afirmar nos seus respectivos Estados. 0 que motivou tantas atitudes depreciativas e em alguns casos até sentimentos de ódio, pelos indícios encontrados, foi a xenofobia contra o italiano. Nesse sentido, trabalhou-se com a hipótese de que o futebol foi uma manifestação cultural que contribuiu, em certa medida, para que alguns

\footnotetext{
${ }^{9}$ MINAS GERAES. Belo Horizonte, p. 2, 19-20 maio 1930.
} 
italianos conseguissem superar adversidades e sobressaíssem com um time composto, em sua maioria, por pessoas dessa origem étnica. Outra questão que se tentou compreender foi como os jogadores do Palestra conseguiram o aprimoramento técnico e físico necessário para sobrepujar os adversários. Nesse caso, a hipótese levantada é de que, por causa do ambiente hostil a que foram submetidos os italianos do Palestra, eles passaram a se desdobrar nos treinamentos e nos jogos para vencer e conquistar títulos.

\title{
METOdOLOGIA E FONTES
}

0 método da história comparada ${ }^{10}$ tem o intuito de extrapolar os estudos locais e regionais como proposto pelo historiador francês Marc Bloch, que utilizou intensamente a comparação e considerava o método comparado um instrumento de uso corrente e com resultados positivos (1963):

\begin{abstract}
O método comparativo tinha o mérito de possibilitar ao observador afastar-se do seu próprio ponto de observação e, ao ultrapassar o caráter individual e único de cada sociedade observada, permitir a passagem da descrição para a explicação de processos históricos, sistematizando assim conhecimentos. Entretanto, a História Comparada na perspectiva de Bloch, atinha-se a espacialidades próximas e a uma mesma temporalidade. A maioria das tentativas feitas no sentido da História Comparada se fundamentava em 'comparar o comparável', em que o conceito de comparação estava necessariamente atrelado a estas fronteiras e/ou períodos tradicionais, confrontando-se preferencialmente sociedades vizinhas, de mesma natureza e coetâneas. ${ }^{11}$
\end{abstract}

Para Bloch, "duas condições são necessárias para que haja, historicamente falando, comparação: uma certa semelhança entre os fatos observados é evidente - e uma certa diferença entre os meios que aconteceram". Nesse mesmo sentido, Barros afirma:

\begin{abstract}
A busca de analogias e diferenças, neste caso, será obviamente imprescindível para que não se tenha um mero quebra cabeças civilizacional. A História Comparada, enfim, não se pode reduzir à mera coletânea de histórias nacionais ou de histórias de civilizações. Ela faz-se de interações, de iluminações recíprocas, e não de meras superposições. ${ }^{12}$
\end{abstract}

\footnotetext{
10 Para maiores informações sobre as origens da História Comparada como modalidade historiográfica específica, v. Barros (2007a).

${ }^{11}$ THEML; BUSTAMANTE. História comparada: olhares plurais, p. 10.

${ }^{12}$ BARROS. História comparada: um novo modo de ver e fazer a História, p. 24.
} 
A partir daí e motivado pelo desejo de ampliação dos olhares e de compreensão da realidade de São Paulo e de Belo Horizonte, no que concerne ao esporte e ao papel dos imigrantes no desenvolvimento do futebol nas capitais mencionadas, estabeleceu-se o recorte temporal que abrange o ano de 1914, ano de fundação do Palestra Itália de São Paulo, até 1933, ano em que ocorreu a profissionalização do futebol em alguns Estados brasileiros. 0 profissionalismo transformou de maneira bem expressiva as relações dos jogadores com os clubes, embora antes de tal regime passar a vigorar já acontecessem relações semiprofissionais nos principais clubes do país, como evidenciado por Rodrigues Filho (2003), Pereira (2000), dentre outros pesquisadores.

A Società Sportiva Palestra Itália de São Paulo foi fundada originalmente em 1914, no extinto salão Alhambra, à época situado próximo à Praça da Sé. Participaram desse encontro, aproximadamente, 46 pessoas, a maioria de origem italiana, e, como consta na primeira carteira social do clube, a entidade almejava ser além de sociedade esportiva, também recreativa e dramática. ${ }^{13}$ De acordo com Streapco (2010), em 27 de agosto de 1914 o jornal Fanfulla informou a composição da primeira diretoria do Palestra Itália fundado na capital paulista.

Já a Societá Sportiva Palestra Itália de Belo Horizonte foi fundada oficialmente no dia 2 de janeiro de 1921, na Casa de Itália, na Rua Tamoios, no centro de Belo Horizonte, e reuniu 95 esportistas de origem italiana. Um dos pontos mais importantes dos dois estatutos era o que determinava que os players das duas entidades só poderiam ser italianos ou filhos de italianos. ${ }^{14}$ Tal exigência foi abolida em 1925, no entanto, o time continuou sendo identificado com os italianos.

A palavra "palestra", de origem grega, significa "academia ou escola onde se pratica atividades físicas". ${ }^{15}$ Entretanto, os dois clubes representaram muito mais do que isso. Em comum tinham o desejo de reunir os membros da colônia nas duas capitais e de ser um projeto elaborado e concretizado para despertar e cultivar o sentimento de italianidade entre os imigrantes ou descendentes. Segundo Duarte,

\footnotetext{
${ }^{13}$ Cf.: CERVO. Início da vida palestrina, 2012.

14 DIÁRIO DE MINAS, Bello Horizonte, p. 2, quarta-feira, 27 abr. 1921.

${ }^{15}$ PALMEIRAS: linha do tempo: 2014-21.
} 
quem sugerira o nome Palestra Italia fora Luigi Cervo. Palestra é palavra de origem grega e, na acepção de que estamos tratando, significa 'local para exercícios; praça em que se praticam esportes, mas que serve também para promover festas e outros eventos'. Para um clube de gente tão ativa e comunicativa, não podia haver melhor denominação. 0 estatuto definira também as cores da agremiação: o verde, branco e vermelho da bandeira italiana. ${ }^{16}$

O Palestra de São Paulo entrou para a APEA em 1916, portanto, dois anos após sua fundação; enquanto o Palestra de Belo Horizonte entrou para a Liga Mineira de Desportes Terrestres (LMDT) em 1921, portanto, no mesmo ano em que foi criado. As duas entidades foram aceitas muito rapidamente nas principais competições dos seus respectivos Estados, o que demonstra a força e a importância que a colônia italiana tinha nas duas capitais. Assim como no caso do Palestra Itália de São Paulo, o uniforme do Palestra mineiro levou as cores da bandeira italiana.

O primeiro título conquistado pelo Palestra de São Paulo ocorreu em 1920, enquanto o Palestra de Belo Horizonte foi campeão em 1926. Contudo, transcorreram-se seis anos para o Palestra de São Paulo ser campeão e cinco anos para o Palestra de Belo Horizonte alcançar o mesmo feito no seu Estado de origem. Eles foram vice-campeões das competições em 1917 e 1922 respectivamente. Podemos perceber que, com todas as dificuldades apresentadas, ainda mais no caso do Palestra Itália de São Paulo, pelas contingências e pelo clima tumultuado ocasionado pela Primeira Guerra Mundial, tudo aconteceu com grande velocidade, tal como os ímpetos da modernidade almejada nas duas capitais que promoveram mudanças importantes na arquitetura, nas novas formas de diversão e de convívio social. 0 estatuto do "Palestra Italia de S. Paulo", fundado em 26 agosto de 1914, apresenta indícios significativos do desejo dos italianos na constituição do time.

\section{TREINAR PELo PALESTRA... JOGAR E VENCER PELA ITÁLIA}

Quem começou a treinar primeiro em São Paulo foi a equipe do Paulistano, em 1918, e serviu de inspiração para outros clubes. A diretoria dessa entidade, além de se preocupar com o "aperfeiçoamento coletivo dos jogadores",17 baseou-se inicialmente e "essencialmente nas condições individuais de cada um conforme a

\footnotetext{
${ }^{16}$ DUARTE. Palmeiras, p. 29.

${ }^{17}$ O ESTADO DE SÃO PAULO. São Paulo, p. 5, 10 nov. 1919.
} 
doutrina que entre nós estava tendo foros de cidade".18 Esse sistema de treinamento adotado pelo Paulistano teve tanto sucesso que o referido clube ganhou o título de “Campeão de 1918”, campeonato muito disputado e que em alguns momentos ameaçou-lhe escapar.

Com a conquista do campeonato, essa equipe deu continuidade às suas sessões de treinamento, buscando novamente a "aquisição dessa glória19". No entanto, com a vitória do Paulistano, outros clubes também estabeleceram formas de treinamento semelhantes, partindo de maiores exigências e especificidades do futebol, fazendo uma análise mais criteriosa do esporte, dos seus fundamentos e das capacidades físicas envolvidas. Ressaltavam-se, sobretudo, os aspectos individuais, muito referenciados por um método intuitivo e aleatório, embasado em tentativa e erro. As equipes de futebol, já no final da segunda década do século XX, em São Paulo, conseguiram aperfeiçoar a preparação dos jogadores e melhorar a performance dos footballers, que naquele momento começavam a ter uma rotina de atletas, já com alguma semelhança com os métodos instituídos posteriormente, com embasamento científico, cujo objetivo passou a ser dar estímulos específicos, nas sessões de treino, para tirar o atleta do estado de equilíbrio. Isso acarretava adaptações no corpo do jogador, tornando-o mais preparado para exercer o futebol, segundo a intensidade e o volume que as partidas passaram a demandar. ${ }^{20}$

As equipes de futebol em São Paulo aperfeiçoaram a preparação dos jogadores porque perceberam que o futebol a cada ano despertava mais interesses. O Corinthians foi um dos clubes que buscaram copiar o modelo que havia dado certo no Paulistano no ano anterior. Em 1919, em matéria publicada no jornal 0 Estado de São Paulo, na vitória do Corinthians contra o Palestra, foram ressaltados os méritos da equipe corinthiana, como o "resultado de um trabalho de preparo feito desde muito tempo com admirável regularidade e progresso". ${ }^{21}$ De fato, o treinamento rigoroso no Corinthians foi instituído no começo de 1919, conforme noticiado em $O$ Estado de São Paulo:

\footnotetext{
${ }^{18}$ O ESTADO DE SÃO PAULO. São Paulo, p. 5, 10 nov. 1919.

19 O ESTADO DE SÃO PAULO. São Paulo, p. 5, 10 nov. 1919.

${ }^{20}$ Cf.: WEINECK. Treinamento ideal, 2003.

21 O ESTADO DE SÃO PAULO. São Paulo, p. 5, 10 nov. 1919.
} 
A vitória que conquistou o Corinthians contra o Palestra é tanto mais meritosa quanto representa o resultado de um trabalho de preparo feito desde muito tempo com admirável regularidade e progresso.

Esse preparo não visou somente, como geralmente se pratica em São Paulo, o aperfeiçoamento coletivo dos jogadores e sim se baseou essencialmente na melhoria das condições individuais de cada um conforme a doutrina que entre nós está tendo foros de cidade desde que a adoção desse sistema permitiu, ao Paulistano, no ano passado, conquistar o título de campeão de 1918 que ameaçava escapar-lhe e este ano, provavelmente, muito contribuirá para a sua provável nova aquisição dessa gloria.

A diretoria do Corinthians dedicou especial atenção e cuidado ao treino individual dos seus footballers, com o intuito, principalmente, de lhes aumentar a resistência de jogo. E foi precisamente por possuírem maior resistência que os seus adversários que os corinthianos no segundo tempo do jogo de ontem fizeram aquela reação, por muitos inesperada, que lhes permitiu alcançar a vitória. Cada vez mais, fica evidenciada a necessidade de todos os footballers praticarem exercícios individuais que os habilitem a usar até o limite máximo todos os conhecimentos técnicos de que possuem. Porque, então, não adotam todos os clubes da primeira divisão esse ótimo método de obrigar seus jogadores a treinarem individualmente todos os dias e coletivamente uma ou duas vezes por semana? Isso nem é impossível nem difícil, pois que algumas das nossas melhores sociedades esportivas desde algum tempo seguem esse sistema do qual tem tirado sempre os melhores resultados. ${ }^{22}$

Nem todas as equipes, entretanto, acreditavam nos métodos de treinamento que passaram a vigorar em algumas associações. Ladislau, em tese apresentada sobre o treinamento esportivo no Brasil, afirma que "as qualidades físicas eram enunciadas de forma muito articulada com suas demandas". 0 autor procurou mapear quais termos foram utilizados para descrever as capacidades físicas importantes a desenvolver nos atletas para o aperfeiçoamento da prática esportiva. ${ }^{23}$

Em Belo Horizonte, os termos empregados no que se refere a preparação dos atletas foram mais vagos, apesar deles também ressaltarem a importância do treinamento, como na notícia veiculada no Diário de Minas do dia 18 de Dezembro de 1921, em que o autor do texto começava a conjecturar o que seria o campeonato de 1922 da seguinte forma: "Vários clubes horizontinos, poderão entrar em campo em 1922 com as mais francas probabilidades de vitória. Esta resultará por certo com maior esforço, da maior constância, do melhor e mais inteligente treinamento. ${ }^{24}$

Em 1922, uma matéria no Diário de Minas confirmou as projeções feitas anteriormente, pois America e Palestra foram apontados como "os dois fortes contendores que se defrontarão, batendo-se pelo título de campeão deste ano, tem

\footnotetext{
${ }^{22}$ UMA observação aproveitável. O Estado de São Paulo, São Paulo, p. 4, 17 nov. 1919.

${ }^{23}$ LADISLAU. Auroras da vitória, p. 97.

${ }^{24}$ DIÁRIO DE MINAS. Belo Horizonte, p. 2-3, 18 dez. 1921.
} 
os seus principais conjuntos em ótimas condições de treino".25 A falta de informações sobre a preparação das equipes fez questionar a todo o momento como era o treinamento dos jogadores em Belo Horizonte. Entretanto, ao se analisar o contexto das publicações referentes à preparação física no Brasil, observou-se que a falta de maiores detalhes sobre as sessões de treino - ou mesmo os poucos termos técnicos empregados nas fontes consultadas - era um reflexo daquele momento em que não se tinha conhecimento sobre este tema.

Os textos publicados nos jornais paulistanos não trazem referências bibliográficas ou teóricas que deem pistas de onde os clubes e os treinadores tenham se embasado para alterar os métodos de preparação das equipes. Tudo leva a crer que um conjunto de fatores pode ter contribuído para sedimentar ampla troca de informações entre os responsáveis pela conduta dos técnicos e a adesão da maioria dos jogadores aos programas de treino. Dentre esses fatores, vale a pena mencionar o acirramento das competições esportivas, a circulação das informações, principalmente dos procedimentos no treinamento dos clubes que se destacavam nos principais campeonatos e a vinda de estrangeiros para o Brasil.

Para Ladislau (2010, p. 89), somente na década de 1930, mais especificamente em 1932, com a publicação do primeiro número da Revista Educação Physica é que o debate sobre a importância do treinamento esportivo ganhou visibilidade: "Logo no primeiro número da Revista Educação Physica, vários artigos expõem a importância do treinamento para o alcance dos objetivos esportivos". É compreensível que com uma publicação especializada, que reunia informações sobre a preparação para a prática esportiva, em muitos lugares do país onde essas revistas circularam, uma gama de conhecimentos e possibilidades de difusão dos métodos de treino foi acessada por pessoas diversas e, sobretudo, profissionais interessados nas várias modalidades e práticas corporais. Até que ponto elas impactaram mudanças no comportamento e na intervenção daqueles que eram responsáveis pela preparação dos atletas é muito difícil especular.

Além da importância atribuída ao preparo físico racional e a ênfase dada às observações das qualidades físicas envolvidas no esporte, como foi enunciado pelos

${ }^{25}$ DIÁRIO DE MINAS. Belo Horizonte, p. 2, 5 mar. 1922. 
jornais de São Paulo a partir de 1919, a novidade que o texto apresenta, considerada de suma importância, é a contratação de um instrutor de Educação Física para atuar na preparação física dos jogadores do Bangu.

Ressalte-se que em Belo Horizonte há muitas informações de que os times existentes na cidade treinavam em dias e horários determinados. A convocação para os treinos eram publicadas nos jornais. Contudo, não foram encontradas maiores informações sobre as rotinas de treino das equipes que disputavam as competições promovidas pela LMDT. Não foram encontrados indícios de que os footballers treinavam individualmente, tampouco de que se exercitavam todos os dias, como algumas equipes paulistanas. Pelas notícias presentes nos jornais, os treinos eram constituídos por jogos coletivos, entre o primeiro e o segundo time das entidades, e de amistosos promovidos contra outras equipes da cidade, contudo não atingiram o grau de exigência e desenvolvimento técnico que os novos rumos do esporte começava a alcançar em São Paulo.

Mesmo para o Palestra Itália de Belo Horizonte "club novíssimo, mas que vem surgindo com todos os requisitos para conquistar os melhores louros", conforme assinala O Diário de Minas de abril de 1921,26 o treinamento dos seus jogadores era condição indispensável para representar bem a colônia italiana da cidade, e também para "trilhar em Minas a mesma róta do valoroso campeão da paulicéa". 270 cronista ainda assinalou que os jogadores do Palestra mostraram-se treinados e resistentes, entretanto faltou-lhes um pouco de técnica. Os players palestrinos que se destacaram positivamente foram Attilio, que o cronista elegeu como o melhor jogador, e Nani, que se distinguiu dos demais por ter demonstrado raro esforço e habilidade.

É importante salientar a preocupação do time do Palestra de Minas Gerais em representar bem e honrar o nome recebido, tal como fazia o clube homônimo do Estado de São Paulo, e, por sua vez, também encher de satisfação os integrantes da colônia instalada nos dois estados.

No Diário de Minas de setembro de 1921, num importante jogo entre o Athletico e o Palestra, que terminou em 1 a 1, o autor da matéria assim resumiu a partida:

\footnotetext{
${ }^{26}$ DIÁRIO DE MINAS. Belo Horizonte, p. 2, 17 abr. 1921.

27 DIÁRIO DE MINAS. Belo Horizonte, p. 2, 17 abr. 1921.
} 
0 jogo mais importante do campeonato da Liga Mineira anteontem realizado foi entre o Athletico e o Palestra, durante o qual atuou como referee, com o maior critério, o dr. Hermeto junior. Foi um match movimentado e cheio de interesse em que o Palestra e o Athletico souberam por á prova os seus requisitos de técnica e treinamento. ${ }^{28}$

Desde os primeiros jogos entre as equipes do Athletico e do Palestra, uma rivalidade acentuada começou a ser instituída, tornando-se, depois de poucos anos transcorridos, a principal rivalidade do futebol no Estado de Minas Gerais. Na citação acima vale destacar a importância atribuída à técnica e ao treinamento, tanto por parte da equipe do Athletico quanto da equipe do Palestra, porém a crônica não apresenta os princípios ou as rotinas de treinamento das equipes belo-horizontinas.

Somente alguns adjetivos podem ser encontrados nas matérias quando os autores se referem ao treinamento das equipes, tal como na narrativa sobre o confronto Palestra e Sete de Setembro, em que, segundo o cronista, "o Sete mostrou um treinamento sadio e vigoroso, que lhe valeu e vai valer". ${ }^{29}$ Nesse jogo, o Palestra foi derrotado com grande superioridade pela equipe do Sete de Setembro, porém não foi possível extrair do texto maiores informações sobre as sessões de treinamento ou os princípios que norteavam a preparação dos jogadores das duas equipes, tal como foi possível identificar em São Paulo.

Da mesma forma, no anúncio da partida que seria disputada entre as equipes da Sociedade Esportiva Palestra Itália de Belo Horizonte e o Villa Nova, o clube de Nova Lima é apresentado da seguinte forma: "Diz-se que o clube de Vila Nova vem excelentemente treinado e disposto para uma luta magnífica. Trata-se, com efeito, de um clube já conhecido em nosso meio e geralmente apreciado nesta capital". 30 Pela falta de descrição dos métodos de treinamento dos times em Belo Horizonte, podese questionar o que significava ser uma equipe excelentemente treinada naquele momento.

Se em Belo Horizonte há poucos indícios de como aconteciam os treinamentos das equipes e como eram executados, em São Paulo as descrições dos treinos são ricas e consistentes a partir de 1919, pois, antes disso, as narrativas

\footnotetext{
${ }^{28}$ DIÁRIO DE MINAS. Belo Horizonte, p. 3, 13 set. 1921.

${ }^{29}$ DIÁRIO DE MINAS. Belo Horizonte, p. 3, 21 jun. 1921.

${ }^{30}$ DIÁRIO DE MINAS. Belo Horizonte, p. 2, 7 jan. 1921.
} 
sobre o treinos encontradas nos jornais são bem parecidas com o contexto da capital mineira - por exemplo, na notícia publicada no Correio Paulistano em julho de 1915: "[...] também a equipe alvi negra, que tanto se tem distinguido no atual campeonato da APSA, pela ótima organização e apurado training do seu time, não desenvolveu, ontem, o seu costumado jogo",31 ou na referência à equipe do Palmeiras que ia disputar um match interestadual contra o Botafogo, em que a primeira foi apresentada como "uma eleven já muito conhecida, treinadíssima e bem organizada". 32

Também em São Paulo as equipes estabeleceram, com o passar dos anos, vários mecanismos para forçar com que os jogadores comparecessem aos treinos, e o principal deles era a exclusão do jogador faltoso dos principais eventos e competições esportivas, como descrito no Correio Paulistano de setembro de 1915 :

Realiza-se hoje um training entre o segundo time e o Rachou team, desta sociedade. Os capitains pedem o comparecimento dos jogadores e dos reservas, para a formação do time que deverá jogar domingo no Velódromo, contra o Palestra Itália. Os que não comparecerem serão excluídos do match. ${ }^{33}$

Apesar de o anúncio do treino não apresentar os conteúdos e as atividades desenvolvidas em campo, pode-se afirmar que os treinamentos eram considerados importantes. Havia um entendimento, possivelmente apoiado por experiências anteriores, que a falta de obrigatoriedade pelo comparecimento dos atletas resultaria num esvaziamento dos treinos e na falta de comprometimento dos jogadores.

Outro aspecto importante de ser salientado é que, com a substancial e intensa circulação dos principais jogadores pelas equipes paulistas, as informações sobre as sessões de treinamento e sobre as atividades que os compunham fizeram com que houvesse uma valorização da preparação dos atletas que formavam as equipes e, concomitantemente, um avanço na prática executada no cotidiano dos "ensaios". No Correio Paulistano de outubro de 1915, na matéria sobre o jogo Santos versus Palestra Itália, o cronista apresentou a equipe santista ressaltando esse aspecto acima mencionado:

\footnotetext{
CORREIO PAULISTANO. São Paulo, p. 4, 12 jul. 1915.

CORREIO PAULISTANO. São Paulo, p. 3, 20 ago. 1915.

${ }^{33}$ CORREIO PAULISTANO. São Paulo, p. 3, 30 set. 1915.
} 
O Santos F. C. Campeão da vizinha cidade, tem-se batido com galhardia contra vários clubes concorrentes ao campeonato paulista e possue uma equipe perfeitamente treinada, além de excelentemente organizada. Alguns dos seus principais elementos são mesmo bastante conhecidos em S. Paulo, onde jogaram brilhantemente, em clubes desta capital. ${ }^{34}$

Embora as equipes treinassem, nem sempre o espetáculo esportivo correspondia às expectativas do público, nem a dos cronistas, como ocorreu no jogo em que o Ypiranga enfrentou o Palestra. 0 jogo, apesar de disputado, não foi bom tecnicamente, nem "primou pelo apuro esportivo",35 como era de se esperar de equipes treinadas e disciplinadas, filiadas à Associação Paulista.

Nas notas dos jornais, os jogos eram apresentados e, em muitos casos, a divulgação para o espetáculo esportivo era construída ressaltando as principais qualidades das equipes, sobressaindo o estado de treinamento em que se encontrava a equipe, pois esse era um importante aspecto a ser levado em consideração por quem buscava assistir a um bom jogo de futebol. "Será portanto um jogo interessantíssimo. 0 time do Palestra é pesado, forte e acha-se em excelentes condições de training; o time do S. Bento é o mesmo que anteontem derrotou o Ypiranga. Portanto, são desnecessários outros pormenores". ${ }^{36}$

Entretanto percebeu-se uma grande mudança nos métodos de treino descritos pela imprensa a partir de 1919. Em crônica publicada no jornal $O$ Estado de São Paulo de novembro de 1919 foram encontrados os princípios que deveriam reger o treinamento das equipes. A matéria, intitulada "As lições do dia", refere-se a um jogo em que o Paulistano derrotou a equipe do Palestra:

A vitória do Paulistano demonstrou primeiro que tudo que uma linha composta de elementos ágeis, ligeiros, de grande poder de movimentação, pode em qualquer caso, desde que esteja bem treinada, enfrentar com inteira vantagem o que entre nós se convencionou a chamar time forte, isto é, um quadro composto de elementos de grande resistência estática, de maior peso, de maior estatura e de maior força. A facilidade de deslocação dos alvi rubros fatigou por fim a defesa palestrina que teve de poder a contida e mobilíssima ofensiva do Paulistano que, era de... (ilegível)... mais de que resistência, requeria um extraordinário poder de atenção. ${ }^{37}$

\footnotetext{
${ }^{34}$ CORREIO PAULISTANO. São Paulo, p. 4, 3 out. 1915.

${ }^{35}$ CORREIO PAULISTANO, São Paulo, p. 2, 291916.

${ }^{36}$ CORREIO PAULISTANO. São Paulo, p. 3, 20 set. 1916.

${ }^{37}$ AS LIÇÕES do dia. O Estado de São Paulo. São Paulo, p. 4, 17 nov. 1919.
} 
Vale destacar que no trecho acima o cronista ressaltou que com o treinamento bem executado uma equipe com atletas mais fracos fisicamente poderia vencer uma equipe constituída por jogadores mais fortes. E foi o que ocorreu, daí o título da matéria, pois essa era realmente a "Lição do dia". Lição que saía do âmbito esportivo e que poderia ser compreendida como uma metáfora, fazendo alusão às situações da vida cotidiana, em que, com empenho, dedicação e trabalho, uma pessoa mais fraca poderia vencer uma pessoa mais forte. A crônica esportiva, ao especializar-se, torna-se pródiga em utilizar esses exemplos que ultrapassam o âmbito do esporte.

Na equipe do Palestra, nesse momento, havia muitos episódios em que os jogadores eram expulsos ou se envolviam em brigas e confusões por entrarem nos lances com força excessiva e com muita agressividade, o que não deixava de ser em razão da grande força física adquirida nos treinamentos, chegando mesmo a intimidar os adversários, que temiam pela sua integridade física.

Na narrativa construída da vitória do Paulistano sobre o Palestra, o autor da crônica destacou que o primeiro princípio responsável pelo êxito do clube era o grande "esforço que forneceram os atletas", e porque, em nenhum instante durante a partida fraquejaram. A boa atuação do Palestra "era em grande parte devido aos exercícios individuais de resistência e de velocidade que desde algum tempo [vinham] obrigatoriamente praticando, como ultimamente, a seu exemplo, está[va] fazendo o S. C. Corinthians". 38

A conclusão a que o autor chegou implicava encontrar um equilíbrio entre o jogo mais agressivo e pesado do Palestra Itália, incentivando, por sua vez, também, o jogo coletivo e as habilidades individuais, de tal forma que surgisse como uma das premissas básicas do jogo a articulação entre as três linhas de jogadores que estavam distribuídos em campo: a linha de defesa, a linha composta pelos jogadores de meiode-campo e a linha de ataque, como demonstrado no trecho a seguir:

Da derrota do Palestra é fácil concluir que o sucesso de um jogo de futebol depende muito mais da coesão, da homogeneidade de um quadro do que da excelência de alguns elementos que o componham. Uma linha de ataque, média ou de defesa é como um todo articulado cujos elementos devem atuar

${ }^{38}$ O ESTADO DE SÃO PAULO. São Paulo, p. 4, 17 nov. 1919. 
harmonicamente entre si e também com os das outras linhas, em perfeita unidade de objetivo e de funcionamento. ${ }^{39}$

Destaque-se, ainda, que o autor da crônica teceu vários elogios ao time do Palestra pela resistência que opunha aos seus adversários, o que demonstrava as ótimas referências dos atletas que compunham a equipe e as boas expectativas que ele vislumbrava para este clube.

Dessa forma, o time do Palestra não ficou atrás por muito tempo das equipes do Paulistano e do Corinthians. Com o recrudescimento do preconceito contra os italianos na cidade de São Paulo e com as inúmeras demonstrações de intolerância e de desrespeito contra eles, o Palestra também começou a treinar de forma rigorosa para enfrentar os outros adversários em condições de ganhar deles.

Uma das crônicas mais significativas desse momento e que registrou os métodos de treinamento adotados pela equipe do Palestra em 1920 foi publicada no jornal 0 Combate em 11 de dezembro, ano em que o Palestra se consagrou campeão da cidade, sobrepujando os demais times que disputavam o principal campeonato da APEA: "O Palestra Itália inegavelmente se destacou sobremaneira nesta campanha. Não se poupou. Adotou os exercícios individuais. Exigiu, dos seus campeões, maiores esforços. Impôs, relativamente, a disciplina entre os seus membros principais". 40

0 objetivo com a referida matéria era anunciar o confronto entre o Palestra Itália e a equipe do Paulistano, que se enfrentariam no dia seguinte, num embate para decidir quem seria o campeão de 1920. As equipes foram apresentadas com as devidas ressalvas, destacando-se a preparação delas. Os jogadores dormiram nas respectivas sedes, procedimento que já naquele momento começara a ser adotado e que décadas mais tarde se tornaria uma forma rotineira e polêmica de confinamento dos atletas, com o intuito de prepará-los para as partidas e competições decisivas, designado de concentração. ${ }^{41}$

\footnotetext{
${ }^{39}$ O ESTADO DE SÃO PAULO. São Paulo, p. 4, 17 nov. 1919.

${ }^{40}$ O COMBATE. São Paulo, p. 1, sábado, 11 dez. 1920.

${ }^{41}$ A chamada "concentração", até os dias de hoje, divide opiniões, sendo rotina em muitos clubes na atualidade. Trata-se de um procedimento de reunir os atletas nos dias que antecedem as principais competições, ou as partidas decisivas, com o objetivo de preparar os atletas em tempo integral, deixando os mesmos longe de qualquer fator negativo que possa interferir no desempenho deles. Vale destacar que não foi encontrada outra "concentração" anterior à citada acima. É possível que esta tenha sido a precursora no futebol brasileiro.
} 
No decorrer desta semana, os rapazes dos dois clubes se preparavam porfiadamente. Todos eles, segundo nos informaram, dormiram nas sédes, afim [sic] de submeterem-se de manhã cedo, a exercícios individuais, constantes, de ginástica sueca, corridas, pulos com corda. Apesar da canícula, estão aptos, os vinte e dois jogadores, a resistir por mais de duas horas..$^{42}$

Para o Palestra, equipe de imigrantes e descendentes de italianos que foram por inúmeras vezes hostilizados ao entrarem no campo de jogo, chamados de "carcamanos, italianos sujos e desertores",43 e outras vezes, em tom pejorativo, de "italianada que pensa querer dominar o Brasil",44 a vitória alcançada no futebol contribuiu para aumentar-lhes ainda mais a autoestima e, também, para reforçar os sentimentos de pertencimento.

Todavia, como verificado em outros momentos e em outros times, o treinamento instituído pelo Palestra Itália despertou resistências iniciais. Nem todos aceitavam se submeter às rotinas pesadas de treino. No Palestra de São Paulo, essa insubordinação teve por parte de um jogador, Alfredo Pedretti, seu principal representante, pois a rotina pesada e desgastante das sessões de preparação foi por ele considerada um "regime ditatorial". 450 referido player, não concordando com o treinamento pesado que passara a vigorar no Palestra, resolveu se ausentar da cidade de São Paulo sem dar nenhuma explicação aos diretores da sua equipe.

Correm várias versões a respeito deste incidente da vida interna do provável campeão deste ano. Como se sabe o clube do Parque Antártica, posto esteja em invejável posição, e tenha dois pontos a mais que o seu mais perigoso antagonista, não se julgando suficientemente seguro, e temendo uma reviravolta da fortuna, tratou de submeter os seus jogadores a rigorosos treinos, de modo a prepará-los para a luta ou lutas com o clube Athletico Paulistano. Pedretti não se quiz [sic] submeter a esse regime ditatorial, sem o que não pode haver turmas fortes, e ausentou-se desta capital, sem dar satisfações aos diretores do seu grêmio. Foi esta a atitude que determinou a resolução extrema por parte da sociedade da rua Libero Badaró. ${ }^{46}$

O jogador, ao abandonar a equipe num momento que antecedia a decisão do campeonato, talvez não esperasse que a reação dos dirigentes fosse tão imediata. A diretoria do Palestra não perdeu tempo em comunicar à imprensa que seu sócio

\footnotetext{
42 O COMBATE. São Paulo, p.1, 11 set. 1920

${ }^{43}$ O ESTADO DE SÃO PAULO. São Paulo, p. 4, 11 jul. 1918.

${ }^{44}$ O ESTADO DE SÃO PAULO. São Paulo, p. 4, 11 jul. 1918.

${ }^{45}$ O COMBATE. São Paulo, p. 1, quinta-feira, 9 dez. 1920.

${ }^{46}$ O COMBATE. São Paulo, p. 1, quinta-feira, 9 dez. 1920.
} 
Alfredo Pedretti, pertencente ao primeiro quadro, havia sido, por indisciplina, eliminado do clube. ${ }^{47}$ Essa decisão foi encarada pela imprensa como uma decisão acertada para se manter a disciplina no esporte, porém em nenhum momento é mencionado o fato de o treinamento desenvolvido pelo Palestra ser excessivo além das condições de os jogadores de suportarem as cargas impostas.

A diretoria do Palestra ainda enviou uma comunicação à Associação Paulista para impedir que Alfredo Pedretti atuasse por outras equipes em território brasileiro, ou que conseguisse regalias, que, segundo o autor da crônica, deveriam ser "conferidas aos que obedecem e sabem guardar a respectiva compostura". ${ }^{48} 0$ receio do Palestra talvez fosse que outros jogadores também pudessem ter a mesma atitude de Pedretti e abandonassem a equipe. Por esse motivo, justificava-se plenamente a punição ao atleta, para manter a ordem, o respeito e a noção de hierarquia, valores que o esporte prometia consolidar.

Como anunciado acima, o Palestra venceu o Paulistano e tornou-se campeão de 1920. Não poderia ser coincidência que mais uma equipe, depois de adotar o treinamento diário, incluindo treinamento individual e coletivo, trabalhando diversas capacidades físicas, com base em uma observação atenta das demandas do futebol, alcançasse o título de campeão, derrotando outras equipes, como o próprio Paulistano e o Corinthians.

Segundo Streapco, o Paulistano e o Palestra Itália eram sempre os primeiros colocados nos campeonatos promovidos pela APEA entre 1917 e 1922, ano em que o Corinthians tornou-se campeão pela primeira vez. ${ }^{49} 0$ que é importante enfatizar na trajetória do Palestra Itália, e que certamente estimulou os jogadores a treinar ainda com mais vontade de superar os adversários, eram os preconceitos que atingiam diretamente os jogadores pertencentes à colônia italiana de São Paulo, quando entravam em campo.

Para se ter uma referência de como os métodos de treinamento mudaram no Palestra Itália, O Estado de São Paulo trouxe, em junho de 1919, a seguinte notícia:

\footnotetext{
${ }^{47}$ O COMBATE. São Paulo, p. 1, quinta-feira, 9 dez. 1920.

48 O COMBATE. São Paulo, p. 1, quinta-feira, 9 dez. 1920.

49 STREAPCO. Cego é aquele que só vê a bola, p. 192.
} 
Os palestrinos fizeram ontem um treino no campo do Corinthians, jogando contra o Mackenzie. Exercitaram-se em driblings, em passes, em shoots, e depois brincaram bastante. Como se fizessem a coisa mais natural deste mundo, fizeram cinco gols, e depois desleixaram no jogo. Resultado: o Mackenzie firmou-se um pouco, alijou as muletas, e fez também dois pontos. ${ }^{50}$

Percebe-se na narrativa do treino acima que a ludicidade, a brincadeira e o jogo coletivo eram preponderantes na equipe italiana. Uma diferença substancial para aqueles métodos adotados pelo mesmo Palestra Itália em 1920 e que foram a causa principal para o abandono de Pedretti, que não suportou os métodos rigorosos de treinamento impostos aos jogadores.

Com a vitória do Palestra Itália em 1920, ficou evidente a importância do trabalho recém-implantado nos clubes da capital paulista, com rotinas de treinamento intensas e diárias, que visavam aperfeiçoar os atletas tanto física, quanto técnica e taticamente, para obterem melhor desempenho e para conquistarem os títulos das competições.

A equipe do Paulistano havia alcançado a supremacia do futebol paulista por ter adotado, primeiro, sessões de treino de acordo com as novas demandas do esporte, que exigiam mais individualmente dos jogadores a cada partida. No entanto, os mesmos procedimentos logo foram reproduzidos por outras equipes que pretendiam alcançar o mesmo desempenho apresentado em campo pelos integrantes do Paulistano, o que, certamente, elevou o nível técnico das partidas, possibilitando confrontos mais acirrados.

\section{CONSIDERAÇõES FINAIS}

Durante a pesquisa, percebeu-se que vencer, para o Palestra Itália, passou a ser uma forma de conseguir reunir e agrupar mais pessoas, que vieram da região onde se constituiu o território italiano após a unificação, em torno de um sentimento de pertencimento a uma comunidade étnica, reforçando, desse modo, a italianidade. Para alcançar o objetivo de ser uma equipe que conquistava títulos nas principais competições da cidade, os jogadores italianos do Palestra não pouparam esforços:

${ }^{50}$ O ESTADO DE SÃO PAULO. São Paulo, p. 4, 30 jun. 1919. 
dedicaram-se, treinaram exaustivamente, além de terem observado o que as equipes que tinham mais êxito no campeonato faziam e começaram a fazer o mesmo.

Nesse sentido, para o Palestra Itália, ganhar os jogos e os campeonatos era algo fundamental, para reforçar a identidade e atrair mais italianos. Dessa forma, mais pessoas dessa origem étnica passaram a identificar-se com o Palestra Itália, à medida que o time passou a ganhar das outras equipes.

Para uma considerável parcela dos imigrantes italianos que sofriam no cotidiano inúmeros percalços e preconceitos, eram insultados e hostilizados, viviam a experiência da não aceitação e ainda conviviam com inúmeras precariedades e restrições, não era interessante pertencer a uma equipe perdedora, pois isso só contribuiria negativamente para diminuir ainda mais o prestígio e aceitação dos italianos nas capitais dos Estados de São Paulo e de Belo Horizonte.

Além de mostrar aos próprios imigrantes italianos que eles poderiam superar os estereótipos e estigmas associados a eles por intermédio do futebol, essa modalidade esportiva passou a representar muito para os brasileiros e para um grande contingente de imigrantes de outras nacionalidades. A partir dessa constatação, percebe-se que o intuito dos dirigentes e dos jogadores italianos era ganhar das outras equipes, subjulgando os outros times às derrotas. Essa era uma forma de compensar, na seara esportiva, todas as humilhações, insultos, picuinhas, desmandos, arbitrariedades e constrangimentos que muitos italianos sofreram ao chegar ao Brasil, que era idealizado como uma terra de oportunidades. Nosso país não correspondeu às expectativas de um grande contingente de italianos, que voltaram para a Itália ao se frustrarem com as péssimas condições de vida oferecidas em território brasileiro.

\section{REFERÊNCIAS:}

BARROS, José D'Assunção. Origens da história comparada: as experiências com o comparativismo histórico entre o século XVIII e a primeira metade do século XIX. Anos 90, Porto Alegre, vol.14, n. 25, p.141-173, jul. 2007a.

BARROS, José D’Assunção. História comparada: um novo modo de ver e fazer a História. Revista de História Comparada, Rio de Janeiro, vol. 1, n. 1, p. 1-30, 2007b. 
BLOCH, Marc. Pour une histoire comparé des sociétes européennes. In:

Melanges historiques. Paris: Sevpen (Bibliotheque Generale de L'École Pratique des Hautes Études), 1963.

CAPELATO, Maria Helena R. A imprensa na história do Brasil. São Paulo: Contexto; Edusp,1988.

CERVO, Luigi. Início da vida palestrina. In: GALUPPO, Fernando Razzo. Morre líder, nasce campeão! - 1942: arrancada heroica palmeirense. São Paulo: Ed. BB, 2012. p 14-23.

DUARTE, Orlando. Palmeiras: o alviverde imponente. São Paulo: Companhia Editora Nacional, 2008.

LADISLAU, Carlos Rogério. Auroras da vitória: letras do treinamento esportivo no Brasil (1920-1968). 2010. 182 f. Tese (Doutorado) - Faculdade de Educação, Universidade Estadual de Campinas (Unicamp) Campinas, SP, 2010.

PALMEIRAS: linha do tempo: 2014-21. Disponível em: <www.palmeiras.com.br/linhadotempo/1914-21 >. Acesso em: 10 nov. 2015.

PEREIRA, Leonardo Affonso de Miranda. Footballmania: uma história social do futebol no Rio de Janeiro, 1902-1938. Rio de Janeiro: Nova Fronteira, 2000 (Coleção Histórias do Brasil)

RODRIGUES FILHO, Mário. O negro no futebol brasileiro. 4. ed. Rio de Janeiro: Mauad, 2003.

STREAPCO, João Paulo F. Cego é aquele que só vê a bola: o futebol em São Paulo e a formação das principais equipes paulistanas: S. C. Corinthians, S. E. Palmeiras e São Paulo F. C. 2010. 228 f. Dissertação (Mestrado em História) Faculdade de Filosofia, Letras e Ciências Humanas, Universidade de São Paulo, São Paulo, 2010.

THEML, Neide; BUSTAMANTE, Regina Maria da Cunha. História comparada: olhares plurais. PHOÎNIX: revista de história comparada, vol. 10, p. 9-30, 2004.

WEINECK, Jürgen. Treinamento ideal: instruções técnicas sobre o desempenho fisiológico, incluindo considerações específicas de treinamento infantil e juvenil. 9. ed. Barueri, SP: Manole, 2003. 